\title{
Correlation of natriuretic peptides and inferior vena cava size in patients with congestive heart failure
}

Virginia Hebl

Marina Y Zakharova

Mariana Canoniero

Daniel Duprez

Santiago Garcia

Division of Cardiovascular Medicine, Department of Internal Medicine, University of Minnesota, Minneapolis, MN, USA
Correspondence: Santiago Garcia,

I Veterans Drive (I I I-C), Minneapolis, MN, ZC: 55417

Tel +I 6124673670

Fax + I 612626 44II

Email garci205@umn.edu
This article was published in the following Dove Press journal:

Vascular Health and Risk Management

6 April 2012

Number of times this article has been viewed

Background: The inferior vena cava (IVC) diameter and degree of inspiratory collapse are used as echocardiographic indices in the estimation of right atrial pressure. Brain-natriuretic peptides (BNPs) are established biomarkers of myocardial wall stress. There is no information available regarding the association between the IVC diameter and BNPs in patients with heart failure and various degrees of systolic performance. The purpose of this investigation is to quantify the degree to which natriuretic peptides (BNP and N-terminal pro-B natriuretic peptide [NT-ProBNP]) and echocardiographic-derived indices of right atrial pressure correlate in this patient population.

Methods: We examined 77 patients (mean age $61 \pm 17$ years, 44\% male) with decompensated heart failure who underwent transthoracic echocardiography and, within a timeframe of 24 hours, determination of BNP and NT-ProBNP levels in venous blood. BNP and NT-ProBNP were analyzed after log transformation. The degree of association was measured by the correlation coefficient using the Pearson's method.

Results: The mean ejection fraction was $50 \% \pm 20 \%$, and $33 \%$ of the study cohort had a remote history of heart failure. The mean IVC diameter was $1.85 \mathrm{~cm} \pm 0.5$, the mean BNP was $274 \mathrm{pg} / \mathrm{mL}$, the confidence interval (CI) was 95\% (95\% CI: 197-382), and the mean NT-ProBNP was $1994 \mathrm{pg} / \mathrm{mL}$ (95\% CI: 1331-2989). There was a positive, albeit small, association between IVC diameter and BNP ( $\mathrm{r}=0.24,95 \% \mathrm{CI}$ : $0.01-0.44 ; P=0.03)$ and NT-ProBNP $(\mathrm{r}=0.27,95 \%$ CI: $0.05-0.47 ; P=0.01)$. Among patients with different degrees of IVC collapse in response to inspiration, values for BNP and NT-ProBNP did not differ substantially ( $P=0.36$ and 0.46 for BNP and NT-ProBNP, respectively).

Conclusion: Natriuretic peptides correlate weakly with IVC size and do not predict changes in response to intrathoracic pressure.

Keywords: heart failure, inferior vena cava, natriuretic peptides

\section{Background}

Congestive heart failure is a leading cause of morbidity and mortality worldwide. ${ }^{1}$ In the USA, over 1,000,000 patients are admitted each year with this diagnosis and $5,000,000$ live with the disease, at a cost of 27.9 billion dollars, which represents the costliest Medicare expenditure. . $^{2,3}$

Accurate estimation of volume status is of paramount importance in the management of acutely decompensated heart failure (ADHF), as patients with elevated filling pressures prior to discharge have higher rehospitalization rates. ${ }^{4}$ Physical examination is inaccurate in estimating filling pressures, and invasive hemodynamic monitoring is infrequently used in the management of patients with ADHF., 
Brain natriuretic peptides (BNPs) and echocardiography are commonly used in clinical practice to assess patients with ADHF. BNP and its precursor, N-terminal pro-B natriuretic peptide (NT-ProBNP), are released in response to myocardial wall stress and correlate well with pulmonary capillary pressure. ${ }^{7,8}$ Echocardiography provides information regarding systolic and diastolic properties, left- and right-sided filling pressures, pulmonary artery pressure, and cardiac output. ${ }^{9}$

The purpose of this investigation was to quantify the degree to which natriuretic peptides (BNP and NT-ProBNP) and echocardiographic-derived indices of right atrial pressure correlate in patients with ADHF.

\section{Methods}

\section{Patients}

Eligible patients were retrospectively identified from our cardiac biomarker and echocardiography electronic databases using unique patient identifiers.

\section{Inclusion criteria}

Patients were eligible for participation in the study if they underwent echocardiographic and biomarker evaluation within 24 hours of each other for the management and/or diagnosis of heart failure at the University of Minnesota Medical Center during the study period from June 1 to December 1, 2006. The setting in which patients underwent echocardiography and biomarker evaluation was the coronary care or telemetry unit ( $88 \%)$, or the emergency department (12\%). For inpatients with more than one biomarker and/or echocardiogram assessment during the index admission, only the one performed within 48 hours of hospital admission was considered for the study.

\section{Exclusion criteria}

Patients with severe left ventricular systolic dysfunction (ejection fraction $[\mathrm{EF}]<35 \%$ ), left ventricular assist devices, and transplant recipients were excluded. Patients with acute coronary syndromes or receiving positive pressure ventilation or inotropic agents were also excluded. The study was approved by the Institutional Review Board and Ethics Committee at the University of Minnesota.

\section{Echocardiography and biomarkers}

Echocardiography was performed by trained sonographers using a transthoracic approach in the standard parasternal, apical, and subcostal views. Two investigators blinded to biomarker levels reviewed all echocardiograms. Cardiac chamber dimensions were estimated from the parasternal long-axis view using two-dimensional (2D)-guided linear measurements, as recommended by the American Society of Echocardiography (ASE). ${ }^{10}$ Right ventricular (RV) function was qualitatively assessed after integration of multiple views, as recommended by the ASE. The main criterion used to assess RV function was the degree of tricuspid annulus displacement toward the apex in systole (normal displacement is $1.5-2 \mathrm{~cm}$ ). ${ }^{10} \mathrm{RV}$ systolic pressure was determined by measuring the peak velocity of the tricuspid regurgitation jet using multiple views. Inferior vena cava (IVC) dimension was measured from a subcostal view $1 \mathrm{~cm}$ from the junction between the IVC and the right atrium during quiet respiration (Figure 1). Changes in IVC dimension in response to respiration were described as collapse $\geq 50 \%$ or $<50 \%$, or no change. The NT-ProBNP and BNP levels were measured using commercially available immunoassays (Elecsys proBNP; Roche Diagnostics, Basel, Switzerland and Triage BNP Test; Biosite Diagnostics, San Diego, CA, respectively).

\section{Statistical analysis}

The baseline characteristics of study patients are presented as percentages for dichotomous variables and mean \pm standard deviation ( $\mathrm{SD})$, or median \pm with interquartile ranges for continuous variables, as appropriate. BNP and NT-ProBNP values were analyzed after log transformation. The degree of association between IVC size and biomarkers was measured by the correlation coefficient using the Pearson's method and depicted in scatter plots. Analysis of variance was used

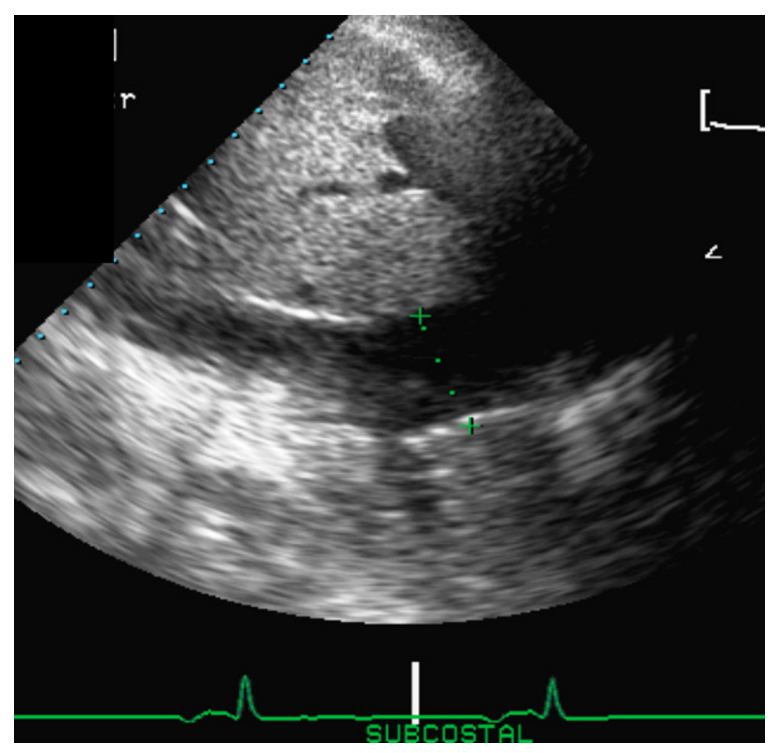

Figure I Examination of the inferior vena cava (IVC) in the subcostal long-axis view $\mathrm{I} \mathrm{cm}$ from the right atria-inferior vena cava junction. 
to perform comparisons across the three groups of IVC collapse. Interobserver agreement between the two readers was assessed in 20 patients using the $\kappa$ statistic, an index that compares agreement against what might be expected by chance. Possible values range from 1 (perfect agreement) via 0 (no agreement above that expected by chance) to -1 (complete disagreement). The software programs SPSS (version 11.0; SPSS Inc, Chicago, IL) and MedCalc for Windows (version 9.5.0.0; MedCalc Software, Mariakerke, Belgium) were used for data analysis.

\section{Results}

\section{Baseline characteristics}

The mean age $( \pm \mathrm{SD})$ of the study group was $61 \pm 17$ years and $44 \%$ were male. A third of the group had a remote history of congestive heart failure or coronary artery disease.

At presentation, $57 \%$ had worsening dyspnea (functional class III-IV), and virtually all patients (99\%) showed one or more physical signs of decompensated heart failure upon examination. These included crackles (17\%), lower extremity edema (49\%), third heart sound (S3) (3.5\%), and elevation in jugular venous pressure (30\%).

The mean ejection fraction, end-systolic dimension, and left atria size were $50 \% \pm 20 \%, 34 \pm 13 \mathrm{~mm}$, and $43 \pm 9 \mathrm{~mm}$, respectively. Background medical therapies at the time of presentation included beta-blockers (54\%), diuretics (64\%), angiotensin-converting enzyme inhibitors or angiotensin receptor blockers (35\%). Other baseline clinical, laboratory, and echocardiographic characteristics are described in Tables 1 and 2.

\section{Inferior vena cava and biomarker assessment}

Interobserver agreement for IVC size and collapsibility measurements was very good ( $\kappa=0.85$ and 0.88 , respectively). The mean IVC diameter was $1.85 \pm 0.5 \mathrm{~cm}$, the mean BNP was $274 \mathrm{pg} / \mathrm{mL}$ (95\% CI: 197-382), and the mean NTProBNP was 1994 pg/mL (95\% CI: 1331-2989). There was a positive correlation between IVC diameter and both BNP and pro-BNP. The correlation coefficient for BNP, as it relates to IVC diameter (Figure 2), was 0.24 (95\% CI: $0.01-0.44 ; P=0.03)$. The correlation coefficient for NTProBNP and IVC diameter (Figure 3) was 0.27 (95\% CI: $0.05-0.47 ; P=0.01)$.

Subgroup analysis stratified by sex showed a more robust association between natriuretic peptides and IVC size among men (correlation coefficient for BNP was $0.33, P=0.05$; and for NT-proBNP it was $0.36 ; P=0.03$ ) when compared to
Table I Baseline characteristics of the study cohort $(n=77)$

\begin{tabular}{|c|c|}
\hline \multicolumn{2}{|l|}{ Demographics } \\
\hline Age (years) $( \pm S D)$ & $61 \pm 17$ \\
\hline Male (\%) & $44 \%$ \\
\hline Caucasian (\%) & $70 \%$ \\
\hline \multicolumn{2}{|l|}{ Medical history } \\
\hline Diabetes (\%) & $30 \%$ \\
\hline Arterial hypertension (\%) & $57 \%$ \\
\hline Hyperlipidemia (\%) & $37 \%$ \\
\hline Coronary artery disease (\%) & $30 \%$ \\
\hline Prior heart failure (\%) & $33 \%$ \\
\hline \multicolumn{2}{|l|}{ Baseline clinical and laboratory data } \\
\hline Inpatient (\%) & $88 \%$ \\
\hline Systolic blood pressure $(\mathrm{mmHg})( \pm \mathrm{SD})$ & $127( \pm 23)$ \\
\hline Diastolic blood pressure $(\mathrm{mmHg})( \pm \mathrm{SD})$ & $75( \pm 13)$ \\
\hline Heart rate $(\mathrm{bpm})( \pm S \mathrm{~S})$ & $84( \pm 17)$ \\
\hline Creatinine clearance $\left(\mathrm{mL} / \mathrm{min} / \mathrm{m}^{2}\right) \pm \mathrm{SD}$ & $51 \pm 20$ \\
\hline Mean brain natriuretic peptide $(95 \% \mathrm{Cl}) \mathrm{pg} / \mathrm{mL}$ & $274(197-382)$ \\
\hline $\begin{array}{l}\text { Mean N-terminal pro-brain natriuretic peptide } \\
(95 \% \mathrm{Cl}) \mathrm{pg} / \mathrm{mL}\end{array}$ & $1994(|33|-2989)$ \\
\hline Serum sodium mEq/L ( \pm SD) & $138( \pm 5)$ \\
\hline Serum potassium mEq/L $( \pm S D)$ & $4.6( \pm 5)$ \\
\hline Hemoglobin mg/dL ( $(\mathrm{SD})$ & II.3 ( \pm 2$)$ \\
\hline
\end{tabular}
minute.

women (correlation coefficient for BNP was $0.14, P=0.35$; and for NT-proBNP it was $0.17 ; P=0.27$ ).

Values for BNP and NT-ProBNP overlapped substantially across different IVC collapsibility subgroups (Figure 4A and B; $P=0.36$ and 0.46 for BNP and NT-ProBNP, respectively). In contrast, baseline IVC diameter correlated well with variations in IVC size in response to changes in intrathoracic pressure (correlation coefficient $=0.46, P<0.001 ;$ Figure 5).

Table 2 Echocardiographic characteristics of study patients $(n=77)$

\begin{tabular}{ll}
\hline End-diastolic dimension (mm) \pm SD & $49 \pm$ II \\
End-systolic dimension (mm) \pm SD & $34 \pm$ I3 \\
Ejection fraction (\%) \pm SD & $50 \pm 20$ \\
Left atrial size (mm) & $43 \pm 9$ \\
Inferior vena cava size (cm) \pm SD & $1.8 \pm 0.5$ \\
Right ventricular systolic pressure (mmHg) $\pm S D$ & $41 \pm 16$ \\
Right ventricular function (\%) & \\
Normal & $74 \%$ \\
Mildly reduced & $9 \%$ \\
Moderately reduced & $13 \%$ \\
Severely reduced & $1 \%$ \\
Unable to assess & $3 \%$ \\
Respiratory collapse of the inferior vena cava & \\
$<50 \%$ & $35 \%$ \\
$\geq 50 \%$ & $34 \%$ \\
Absent & $31 \%$ \\
\hline
\end{tabular}

Abbreviation: SD, standard deviation. 


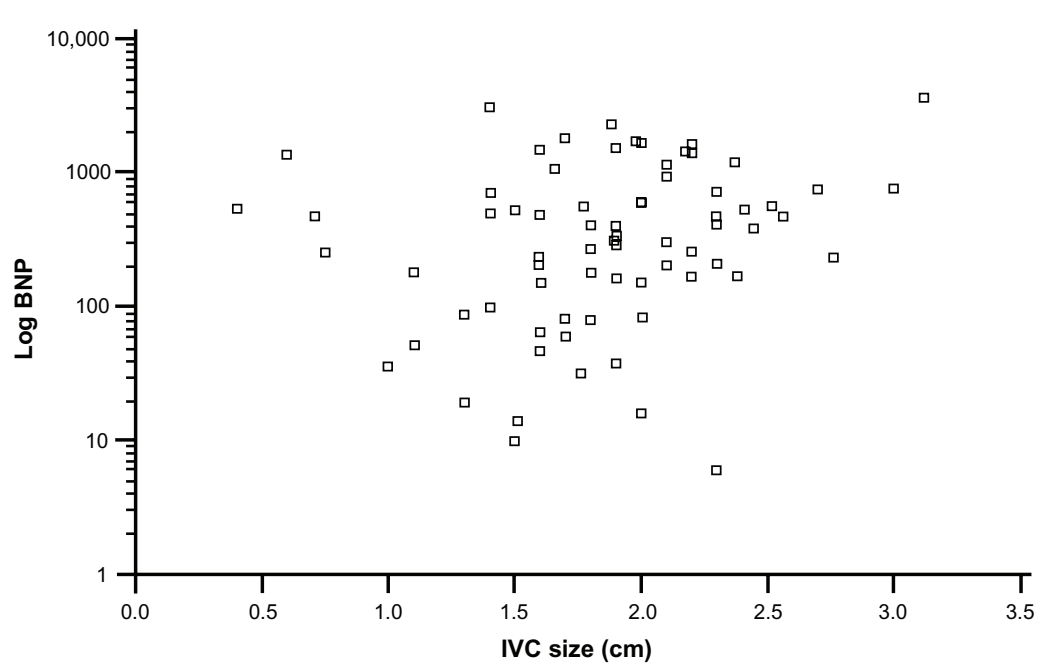

Figure 2 Scatter plot of log-transformed brain natriuretic peptide (BNP) and inferior vena cava size (IVC).

Notes: Correlation coefficient $r=0.24$, confidence interval $(\mathrm{Cl}): 0.0 \mathrm{I}-0.44 ; P=0.03$.

\section{Discussion}

In this cohort of patients with acute heart failure and preserved or mildly reduced systolic function, we found a positive association between the natriuretic peptides BNP and NT-ProBNP, and IVC size. In contrast, neither BNP nor NT-ProBNP showed a good correlation with the response of the IVC to changes in intrathoracic pressure. Using the $100 \mathrm{r}^{2}$ formula, which is the percentage of the variability of the data that is explained by the association of the two variables, it can be concluded that biomarkers explain less than $10 \%$ of the variability in IVC dimensions without major differences between BNP and NTProBNP. ${ }^{10}$ The results of this study suggest that commonly used indices of right atrial pressure (IVC size and response to respi- ration) and left ventricular end-diastolic pressure (natriuretic peptides) complement each other by providing information about filling pressures in both heart chambers.

Among patients with systolic heart failure, BNP has been shown to correlate with IVC size. ${ }^{11}$ The magnitude of this association was stronger with systolic heart failure patients than in our study of patients with preserved or mildly reduced ejection fraction. This phenomenon, whereby echocardiography-derived indices of filling pressures perform better among patients with systolic dysfunction, has been reported previously for E/e' and other indices of pulmonary capillary pressure. ${ }^{12}$ Alternatively, patients with better preserved EF may not have as much elevation in right

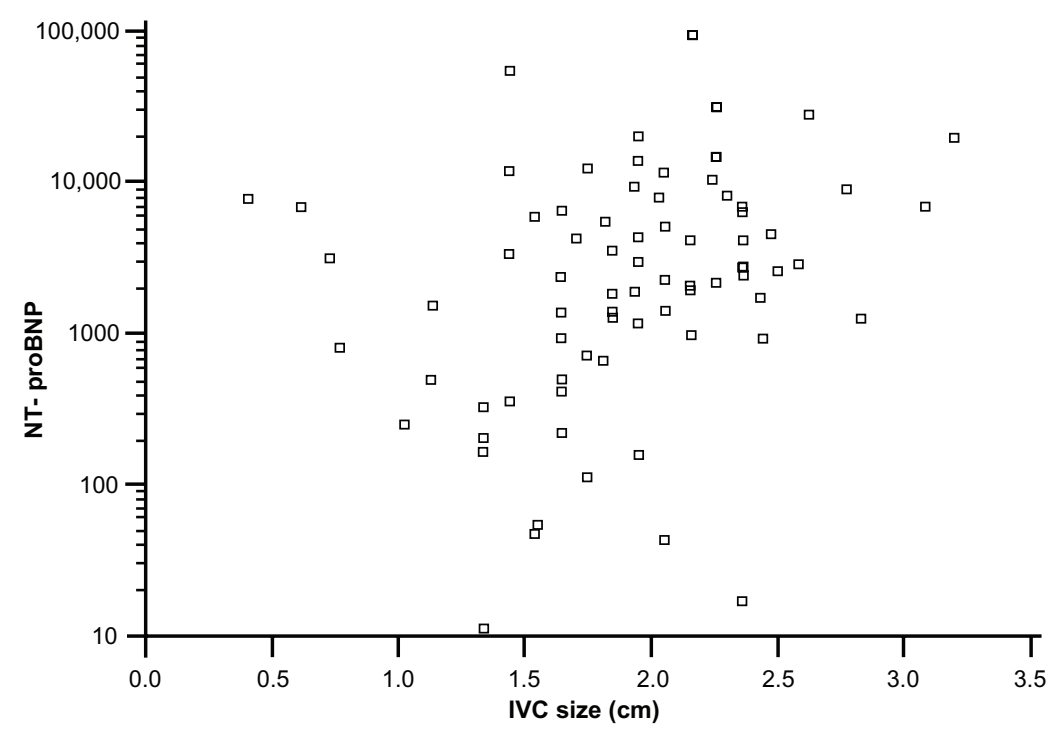

Figure 3 Scatter plot of log-transformed N-terminal pro-brain natriuretic peptide (NT-ProBNP) and inferior vena cava size (IVC). Notes: Correlation coefficient $r=0.27$, confidence interval $(C I): 0.05-0.47 ; P=0.01$. 
A

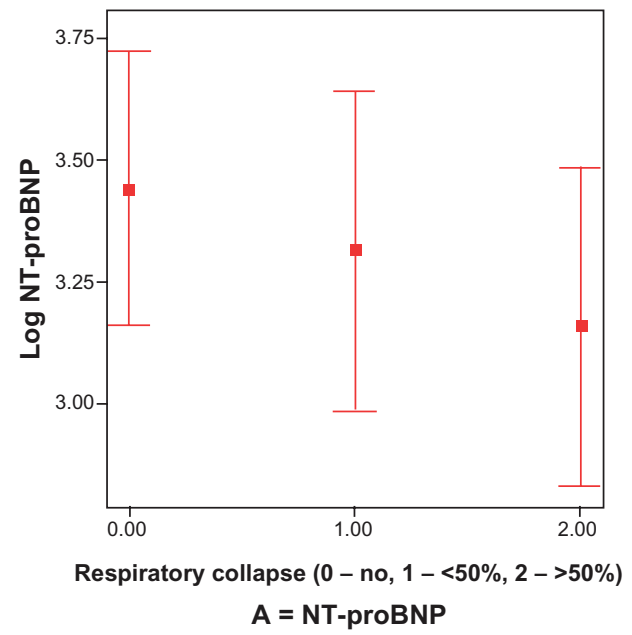

B

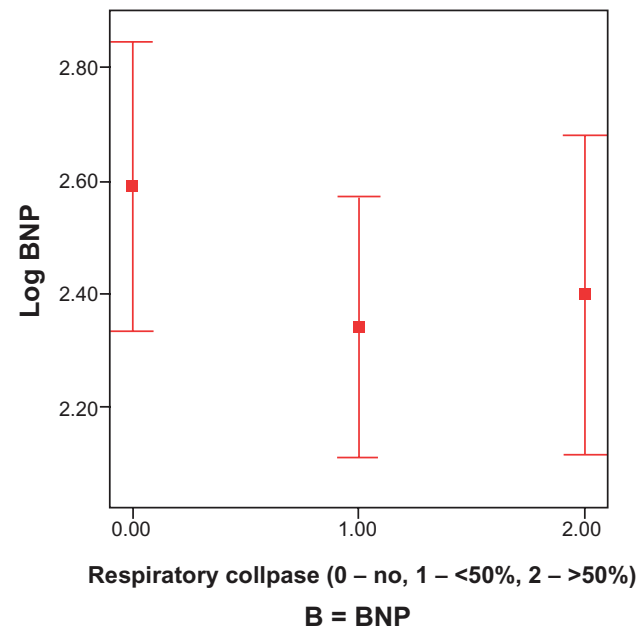

Figure 4 Scatter plot of log-transformed values of (A) N-terminal pro-brain natriuretic peptide (NT-ProBNP) and (B) brain natriuretic peptide (BNP) (Y axis) according to respirophasic changes in the inferior vena cava (IVC) size ( $X$ axis) $(P=0.46$ and 0.36 for NT-ProBNP and BNP, respectively).

atrial pressure as those with systolic heart failure, despite the presence of RV diastolic dysfunction. ${ }^{13}$

The finding of a lack of correlation between natriuretic peptides and IVC among women is interesting, although caution is advised when interpreting this finding due to the small sample size (type II statistical error). This finding needs to be confirmed in larger studies.

The mechanism underlying increased natriuretic peptides in females is unclear, although Redfield et al reported $21 \%$ higher BNP levels in women taking hormone replacement therapy, which may suggest that estrogens play a role in the increased levels. ${ }^{14}$

The IVC is a compliant intra-abdominal vessel that changes in diameter in response to fluctuations in right atrial

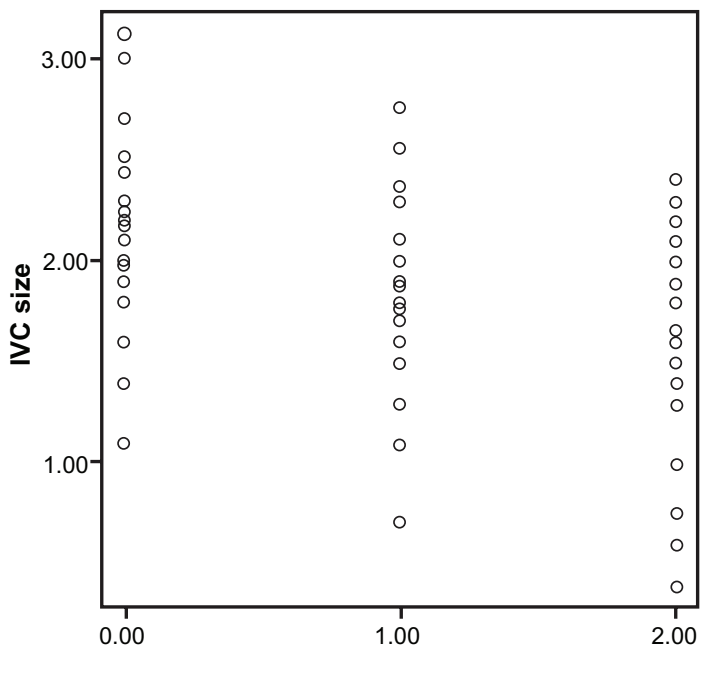

Figure 5 Scatter plot showing the relationship between inferior vena cava (IVC) size $\mathrm{cm}$, and the degree of IVC inspiratory collapse (analysis of variance $P<0.00 \mathrm{I}$ ). pressure and volume overload. ${ }^{15}$ As shown in our study, the degree of IVC collapse in response to intrathoracic pressure correlates with baseline IVC diameter, and when used in conjunction with IVC size provides an accurate, noninvasive estimation of right atrial pressure. ${ }^{16} \mathrm{~A}$ rapid assessment of IVC physiology could be performed at the bedside by a noncardiologist and also in the emergency department for patients with unexplained dyspnea. ${ }^{17,18}$

BNP and NT-ProBNP are useful in the diagnosis of ADHF and provide independent prognostic information that allows optimization of medical therapies. ${ }^{7,8,19,20}$ Both natriuretic peptides and echocardiography are routinely used in the management of patients with decompensated heart failure. ${ }^{21}$ Our data suggests that natriuretic peptides and echocardiography provide complementary data with regard to the status of right- and left-sided filling pressures.

\section{Limitations}

Our study has several limitations intrinsic to this type of study design (retrospective chart review). First, invasive hemodynamic measurement was not routinely applied in our study population. Second, the majority of the patients included in the study were hospitalized with decompensated heart failure at the time of the study. Therefore, the association between natriuretic peptides and IVC dimension described may not apply to an outpatient, compensated heart failure cohort. Third, we did not perform serial IVC or biomarker measurements, nor did we collect information regarding medication administration that could potentially influence both natriuretic peptides and IVC size (ie, diuretics) during the index admission. Therefore, we are unable to comment on any dynamic changes that may occur between IVC size and 
natriuretic peptides during the treatment of ADHF. Finally, elevation in natriuretic peptides is not solely a reflection of cardiac filling pressures. ${ }^{22,23}$ Factors known to have an impact on natriuretic peptides, such as age, sex, creatinine clearance, and body mass index, could have influenced our results and may explain the weak correlation between natriuretic peptides and IVC size and collapsibility.

\section{Conclusion}

Among patients with acutely decompensated heart failure, natriuretic peptides correlate weakly with IVC size and do not predict changes in response to intrathoracic pressure. These data suggest a complementary role for right-sided echocardiography and biomarker evaluation.

\section{Disclosure}

The authors report no conflict of interest in this work.

\section{References}

1. Yusuf S, Reddi S, Ôunpuu S, Anand S. Global burden of cardiovascular diseases. Part I: General considerations, the epidemiologic transition, risk factors, and impact of urbanization. Circulation. 2001;104:2746-2753.

2. Hunt SA, Abraham WT, Chin MH, et al. ACC/AHA 2005 guideline update for the diagnosis and management of heart failure in the adult: a report of the American College of Cardiology/American Heart Association Task Force on Practice Guidelines (Writing Committee Update the 2001 Guidelines for the Evaluation and Management of Heart Failure). Available from: http://www.acc.org/clinical/guidelines/failure/index. pdf. Accessed on March 20, 2012.

3. Massie BM, Shah NB. Evolving trends in the epidemiologic factors of heart failure: rationale for preventing strategies and comprehensive disease management. Am Heart J. 1997;133:703-712.

4. Whalley GA, Doughty RN, Gamble GD, et al. Pseudonormal mitral filling pattern predicts hospital re-admission in patients with congestive heart failure. J Am Coll Cardiol. 2002;39:1787-1795.

5. Wang CS, FitzGerald M, Schulzer M, et al. Does this dyspneic patient in the emergency department have congestive heart failure? JAMA. 2005;294:1944-1956.

6. Wiener RS, Welch G. Trends in the use of the pulmonary artery catheter in the United States,1993-2004. JAMA. 2007;298:423-429.

7. Lainchbury JG, Campbell E, Frampton CM, Yandle TG, Nicholls MG, Richards AM. Brain natriuretic peptide and n-terminal brain natriuretic peptide in the diagnosis of heart failure in patients with acute shortness of breath. J Am Coll Cardiol. 2003;42(4):728-735.

8. Maisel AS, McCord J, Nowak RM, et al; Breathing Not Properly Multinational Study Investigators. Bedside B-Type natriuretic peptide in the emergency diagnosis of heart failure with reduced or preserved ejection fraction. Results from the Breathing Not Properly Multinational Study. J Am Coll Cardiol. 2003;41(11):2010-2017.

Vascular Health and Risk Management

\section{Publish your work in this journal}

Vascular Health and Risk Management is an international, peerreviewed journal of therapeutics and risk management, focusing on concise rapid reporting of clinical studies on the processes involved in the maintenance of vascular health; the monitoring, prevention and treatment of vascular disease and its sequelae; and the involvement of
9. Kirkpatrick JN, Vannan MA, Narula J, Lang RM. Echocardiography in heart failure: Applications, utility, and new horizons. J Am Coll Cardiol. 2007;50:381-396.

10. Lang RM, Bierig M, Devereux RB, et al. Recommendations for chamber quantification: a report from the American Society of Echocardiography's guidelines and standards committee and the chamber quantification writing group, developed in conjunction with the European Association of Echocardiography, a branch of the European Society of Cardiology. J Am Soc Echocardiogr. 2005;18:1440-1463.

11. Pudil R, Tichy M, Praus R, Blaha V, Vojacek J. NT-proBNP and echocardiographic parameters in patients with acute heart failure. Acta Medica (Hradec Kralove). 2007;50(1):51-56.

12. Ommen SR, Nishimura RA, Appleton CP, et al. Clinical utility of doppler echocardiography and tissue-doppler imaging in the estimation of left ventricular filing pressures: a comparative simultaneous dopplercatheterization study. Circulation. 2000;102:1788-1794.

13. Yu CM, Sanderson JE, Chan S, Yeung L, Hung YT, Woo KS. Right ventricular diastolic dysfunction in heart failure. Circulation. 1996;93:1509-1514.

14. Redfield MM, Rodeheffer RJ, Jacobsen SJ, Mahoney DW, Bailey KR, Burnett JC. Plasma brain natriuretic peptide concentration: impact of age and gender. J Am Coll Cardiol. 2002;40:976-982.

15. Stein JH, Neumann A, Marcus RH. Comparison of estimates of right atrial pressure by physical examination and echocardiography in patients with congestive heart failure and reasons for discrepancies. Am J Cardiol. 1997;80:1615-1618.

16. Kirscher BJ, Himelman RB, Schiller NB. Noninvasive estimation of right atrial pressure from the inspiratory collapse of the inferior vena cava. Am J Cardiol. 1990;66:493-496.

17. Kimura BJ, Shaw DJ, Agan DL, Amundson SA, Ping AC, DeMaria AN. Value of a cardiovascular limited ultrasound examination using a hand-carried ultrasound device on clinical management in an outpatient medical clinic. Am J Cardiol. 2007;100:321-325.

18. Jang T, Aubin C, Naunheim R, Char D. Ultrasonography of the internal jugular vein in patients with dyspnea without jugular venous distension on physical examination. Ann Emerg Med. 2004;44(2):160-168.

19. Hartmann F, Packer M, Coats AJ, et al. Prognostic impact of plasma $\mathrm{N}$-terminal pro-brain natriuretic peptide in severe chronic congestive heart failure: a sub-study of the Carvedilol Prospective Randomized Cumulative Survival (COPERNICUS) trial. Circulation. 2004;110:1780-1786.

20. Gackowski A, Isnard R, Golmard JL, et al. Comparison of echocardiography and plasma B-type natriuretic peptide for monitoring the response to treatment in acute heart failure. Eur Heart J. 2004;20:1788-1796.

21. Goonewardena SN, Gemignani A, Ronan A, et al. Comparison of handcarried ultrasound assessment of the inferior vena cava and $\mathrm{N}$-terminal pro-brain natriuretic peptide for predicting readmission after hospitalization for acute decompensated heart failure. JACC Cardiovasc Imaging 2008;1:595-601.

22. Daniels LB, Maisel AL. Natriuretic peptides. J Am Coll Cardiol. 2007;50:2357-2368.

23. Galasko GIW, Lahiri A, Barnes SC, Collison P, Senior R. What is the normal range for $\mathrm{N}$-terminal pro-brain natriuretic peptide? How well does this normal range screen for cardiovascular disease? Eur Heart J. 2005;26:2269-2276.

metabolic disorders, particularly diabetes. This journal is indexed on PubMed Central and MedLine. The manuscript management system is completely online and includes a very quick and fair peer-review system, which is all easy to use. Visit http://www.dovepress.com/ testimonials.php to read real quotes from published authors. 